\title{
DATA BASE KEANEKARAGAMAN HAYATI PERIKANAN PERAIRAN UMUM DARATAN DI SULAWESI
}

\author{
Adriani Sri Nastiti Krismono \\ Peneliti pada Loka Riset Pemacuan Stok Ikan, Jatiluhur-Purwakarta \\ Teregristrasi I tanggal: 19 Nopember 2008; Diterima setelah perbaikan tanggal: 9 Pebruari 2009; \\ Disetujui terbit tanggal: 19 Maret 2009
}

\begin{abstract}
ABSTRAK
Data base keanekaragaman hayati perikanan perairan umum daratan di Sulawesi dibangun dengan tujuan mengumpulkan dan mengorganisasi data keanekaragaman hayati perikanan perairan umum daratan Sulawesi, agar data base tersebut mudah diakses dan dimanfaatkan sebagai bahan informasi keanekaragaman hayati perairan umum daratan di Indonesia. Metode pembangunan data base keanekaragaman hayati tersebut disusun dalam sebuah aplikasi program Microsoft Access 2000, dan didukung oleh referensi standar taxon list flora dan fauna, batas administrasi Indonesia, dan referensi geografi atau georeference. Berdasarkan pada metode ini, informasi yang dihasilkan dapat ditumpang tindihkan (overlay) untuk memperoleh gambaran, baik secara tekstual maupun secara spasial dengan lokasi yang menjadi cor. Sumber data berasal dari laporan penelitian Pusat Riset Perikanan Tangkap, Perguruan Tinggi, Lembaga IImu Pengetahuan Indonesia, Balai Penelitian Perikanan Air Tawar, Dinas Kelautan dan Perikanan Sulawesi Selatan, Badan Konservasi Sumber Daya Alam di lingkup Kabupaten Sulawesi Selatan, karya tulis mahasiswa Universitas Ratulangi Manado. Aktual data base keanekaragaman hayati perikanan perairan umum daratan Sulawesi diperoleh dari sejumlah badan air yang sudah diteliti sekitar 214 buah yang terdiri atas 175 buah sungai dan rawa dengan persentase sungai yang terbanyak di Sulawesi Selatan, danau di Sulawesi Utara, sedangkan perairan waduk hanya dilakukan di satu lokasi yaitu Waduk Bili-Bili di Sulawesi Selatan yang dilengkapi dengan data ikan, plankton, bentos, serangga air, tumbuhan air, dan kualitas air. Berdasarkan pada aplikasi data base diketahui bahwa perlu melengkapi data keanekaragaman hayati perairan sungai, data kualitas air yang baru tercatat sekitar 29 badan air dari 214 badan air.
\end{abstract}

\section{KATAKUNCI: data base, keanekaragaman hayati, perairan umum daratan, Sulawesi}

\section{PENDAHULUAN}

Informasi tentang keanekaragaman hayati perikanan perairan umum daratan di Sulawesi pada umumnya tersimpan dalam bentuk laporan intern kegiatan, jurnal penelitian serta buku-buku catatan lapangan peneliti yang belum diterbitkan. Pembangunan aplikasi data base keanekaragaman hayati perikanan perairan umum daratan di Sulawesi diawali oleh sebuah pemikiran bahwa data adalah merupakan modal dasar yang tak ternilai harganya yang dimiliki oleh lembaga penelitian. Seperti halnya dilakukan oleh Global Biodiversity Information Facilities yang telah menghimpun data keanekaragaman hayati dari simpul yang bergabung di dalamnya berasal dari beberapa negara di seluruh dunia termasuk Indonesia. Institusi global ini telah mempublikasikan 10 juta record data keanekaragaman hayati yang bersifat public domain (milik masyarakat) dalam websitenya (GBIF, 2005).

Disadari bahwa data keanakeragaman hayati perikanan perairan umum daratan Sulawesi sangat banyak, sebagai contoh di Sulawesi Selatan perairan umum daratannya cukup luas, yaitu sekitar 300 buah sungai dan 86.000 ha danau dan rawa (Haryono \&
Munim, 1994). Sulawesi Utara memiliki luas perairan sekitar 95.000 ha yang dihuni oleh jenis-jenis ikan yang bernilai ekonomis penting dan merupakan sumber mata pencaharian nelayan setempat (Haryono, 1994), sedangkan luas perairan umum daratan yang dimanfaatkan baru sekitar 28.352 ha (Hadiwijaya, 1982). Aktual data base baru terkumpul sekitar 200 data (record) untuk diorganisir dengan baik. Oleh karena itu, penyusunan data base secara elektronik sangat penting dan diharapkan dapat menghasilkan suatu data dan informasi yang memiliki nilai strategis yang tinggi.

Tujuan dari penyusunan aplikasi data base adalah mengumpulkan dan mengorganisasi data keanekaragaman hayati perikanan perairan umum daratan Sulawesi, agar data base tersebut mudah diakses dan dimanfaatkan sebagai bahan informasi keanekaragaman hayati perairan umum daratan di Indonesia. Manfaat yang diperoleh dari penyusunan aplikasi data base ini adalah untuk memberikan layanan kepada peneliti atau user lainnya sehingga data lebih mudah dicari, dianalisis, dan jika ada data baru updating data dapat dilakukan dengan mudah. Aplikasi data base keanekaragaman hayati perikanan perairan umum daratan Sulawesi bersifat off line 
(rahasia), artinya bila data atau informasi ini dibutuhkan oleh peneliti atau user lainnya seijin dari lembaga, dalam hal ini Pusat Riset Perikanan Tangkap, Badan Riset Kelautan dan Perikanan.

\section{METODE PEMBANGUNAN APLIKASI DATA BASE}

Aplikasi data base keanekaragaman hayati perikanan perairan umum daratan Sulawesi disusun dalam sebuah program Microsoft Access 2000, dan didukung oleh referensi standar taxon list flora dan fauna (Roemantyo et al., 2004a), batas administrasi Indonesia (BPS, 1996), dan referensi geografi atau georeference (Roemantyo et al., 2004b). Berdasarkan pada metode ini, informasi yang dihasilkan dapat ditumpang-tindihkan (overlay) untuk memperoleh gambaran baik secara tekstual maupun spasial. Data base keanekaragaman hayati perikanan perairan umum daratan di Sulawesi terdiri atas nama dan tipe badan air (danau, waduk, rawa, dan sungai) termasuk morfometri, ketinggian lokasi, dan posisi badan air dari permukaan laut yang dilengkapi dengan peta, biota air yang dilengkapi dengan gambar (ikan, plankton, bentos, tumbuhan air, dan serangga air), serta kualitas air. Data base yang dikumpulkan dari hasil penelitian tahun 1984-2005.
Sumber data yang dikumpulkan berasal dari:

1. Hasil survei yang dilaksanakan oleh Tim Peneliti dari Pusat Riset Perikanan Tangkap dan Perguruan Tinggi seperti Universitas Sam Ratulangi Manado, Universitas Hasannudin Makassar, Universitas Indonesia Jakarta dan Institut Pertanian Bogor, serta Pusat Penelitian Limnologi-Lembaga IImu Pengetahuan Indonesia.

2. Perjalanan dinas Tim Peneliti Lembaga IImu Pengetahuan Indonesia.

3. Jurnal Penelitian Balai Penelitian Perikanan Air Tawar.

4. Dinas Kelautan dan Perikanan Sulawesi Selatan.

5. Badan Konservasi Sumber Daya Alam di beberapa daerah di Sulawesi Selatan.

6. Skripsi dan Tesis mahasiswa dari Universitas Sam Ratulangi Manado.

Tahapan pembuatan aplikasi sebagai berikut:

1. Membuat beberapa tabel di antaranya tabel lokasi, ikan, plankton, bentos, tanaman air, dan kualitas air dengan lokasi menjadi cor (Tabel 1, Gambar 1a, b).

2. Membuat tabel format field data yang dikumpulkan (Tabel 1).

Tabel 1. Format field data yang dikumpulkan

\begin{tabular}{|c|c|c|c|c|c|c|}
\hline Lokasi & Ikan & Plankton & Betos & Tanaman air & Serangga air & Kualitas air \\
\hline Nama pengamat & Determiner & Determiner & Determiner & Determiner & Determiner & Nama pengamat \\
\hline \multicolumn{7}{|l|}{ Tanggal } \\
\hline pengamatan & Tanggal & Tanggal & Tanggal & Tanggal & Tanggal & Tanggal \\
\hline Nama badan air & Famili & Famili & Famili & Famili & Famili & Waktu pengamatan \\
\hline Tipe badan air & Genus & Genus & Genus & Genus & Genus & Cuaca \\
\hline Stasiun & Spesies & Spesies & Spesies & Spesies & Spesies & Kedalaman \\
\hline Habitat & Nama daerah & Nama daerah & Nama daerah & Nama daerah & Nama daerah & Kecerahan \\
\hline Ketinggian & Dokumen & Dokumen & Dokumen & Dokumen & Dokumen & Suhu udara \\
\hline Longitude & Gambar & Gambar & Gambar & Gambar & Gambar & Suhu air \\
\hline Latitude & Hasil tangkapan & & & & & Intensitas cahaya \\
\hline Detail badan air & Alat tangkap & & & & & Total padatan terlarut \\
\hline \multicolumn{2}{|l|}{ Pola pengelolaan } & & & & & Daya hantar listrik \\
\hline \multicolumn{2}{|l|}{ Gambar } & & & & & $\mathrm{pH}$ \\
\hline \multicolumn{2}{|l|}{ Pulau } & & & & & $\mathrm{CO} 2$ \\
\hline \multicolumn{2}{|l|}{ Provinsi } & & & & & $\mathrm{O} 2$ \\
\hline \multicolumn{2}{|l|}{ Kabupaten } & & & & & BOD 5 hari \\
\hline \multicolumn{2}{|l|}{ Kecamatan } & & & & & Total organik \\
\hline \multicolumn{2}{|l|}{ Desa } & & & & & Total alkalinitas \\
\hline \multicolumn{2}{|l|}{ Jarak ke lokasi } & & & & & $\mathrm{Ca}$ \\
\hline \multirow[t]{8}{*}{ Arah ke lokasi } & & & & & & $\mathrm{Mg}$ \\
\hline & & & & & & $\mathrm{Fe}$ \\
\hline & & & & & & Amonium \\
\hline & & & & & & Amoniak \\
\hline & & & & & & Nitrat \\
\hline & & & & & & Nitrit \\
\hline & & & & & & Fosfat \\
\hline & & & & & & Sulfat \\
\hline
\end{tabular}






Gambar 1a. Desain tabel lokasi.

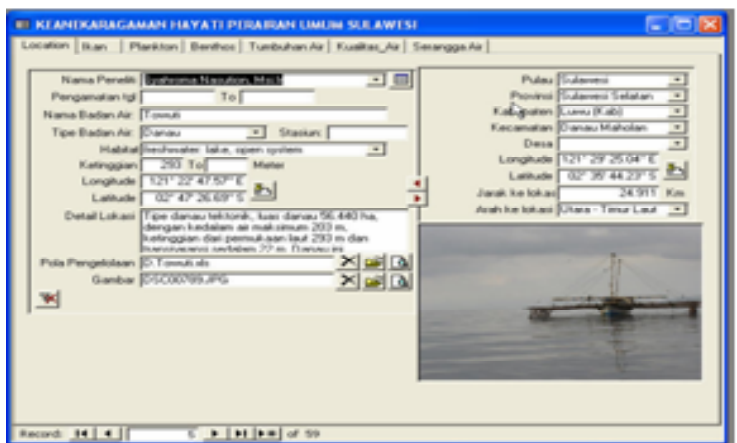

Gambar 2a. Form data lokasi.

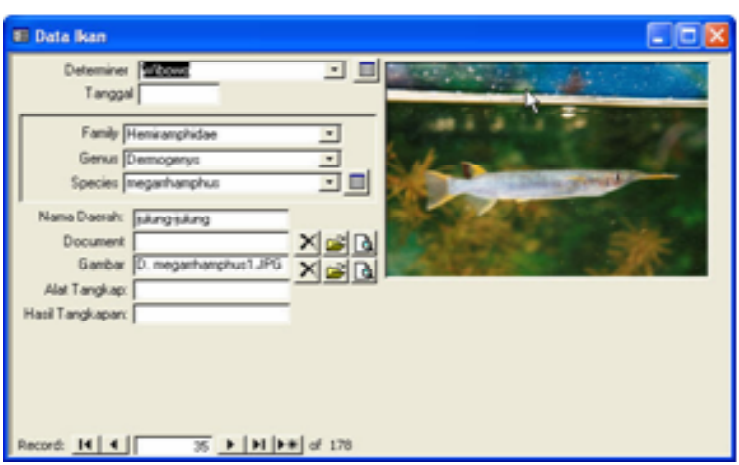

Gambar 2c. Form data ikan yang dilengkapi dengan Spesies 2000.

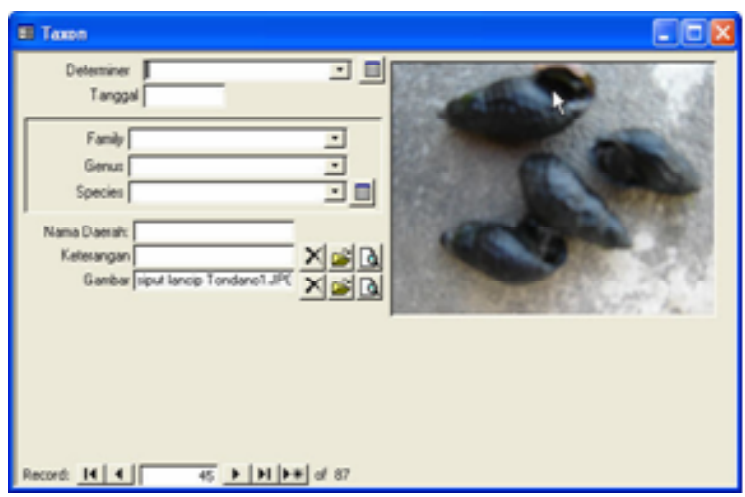

Gambar 2e. Form data bentos dilengkapi dengan Spesies 2000.

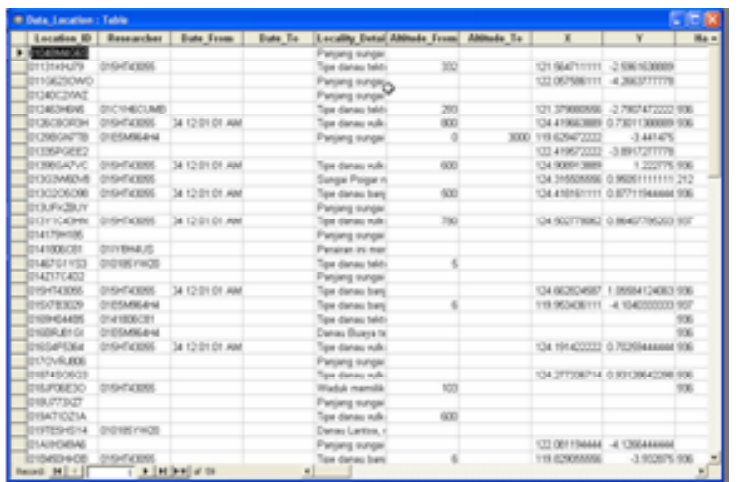

Gambar 1b. Tabel data lokasi.

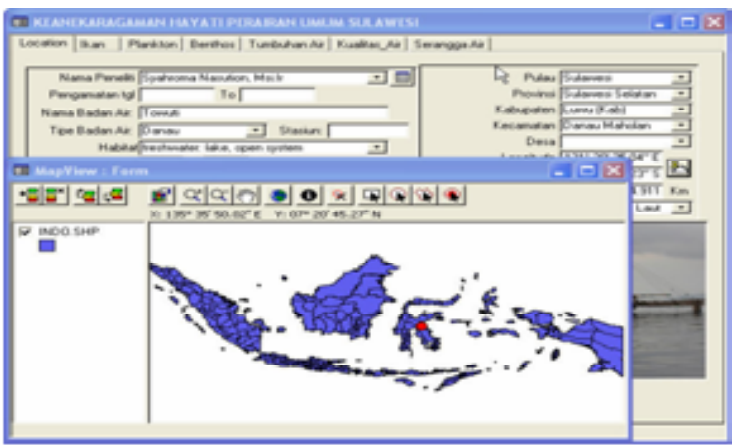

Gambar 2b. Form data lokasi dilengkapi dengan map.

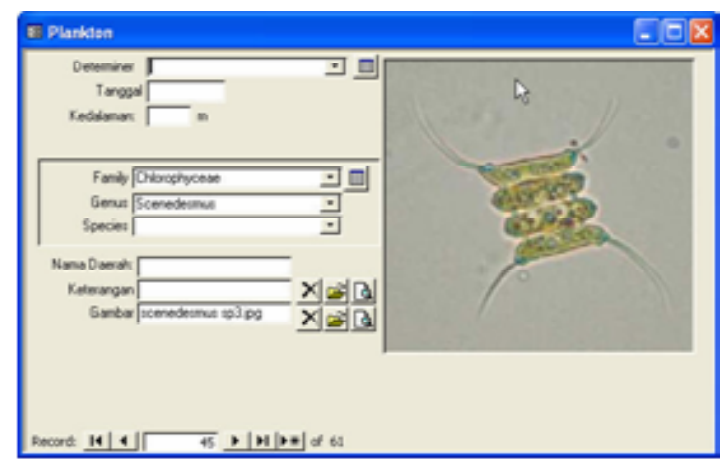

Gambar 2d. Form data plankton dilengkapi dengan Spesies 2000.



2f. Form data serangga air dilengkapi dengan Spesies 2000. 




Gambar 2g. Form data plankton dilengkapi dengan Spesies 2000.

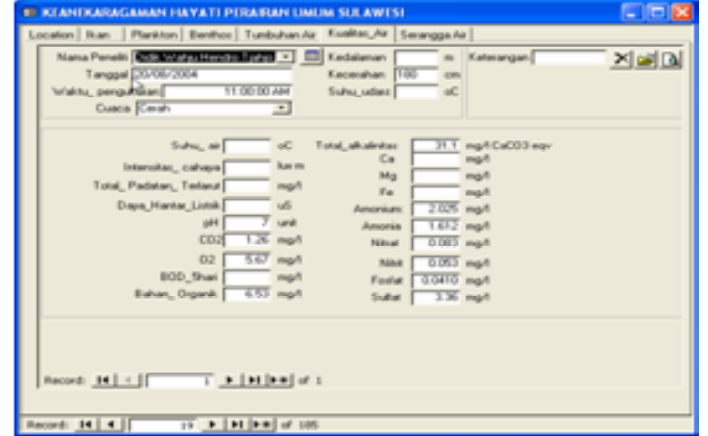

Gambar 2h. Form data kualitas air.

Tabel 2. Data base keanekaragaman hayati perikanan perairan umum daratan di Sulawesi yang telah dikumpulkan

\begin{tabular}{|c|c|c|c|c|c|c|c|c|}
\hline \multirow{2}{*}{ Provinsi } & \multicolumn{2}{|c|}{ Badan air } & \multirow{2}{*}{ Ikan } & \multirow{2}{*}{ Plankton } & \multirow{2}{*}{ Bentos } & \multirow{2}{*}{$\begin{array}{c}\text { Tumbuhan } \\
\text { air }\end{array}$} & \multirow{2}{*}{$\begin{array}{c}\text { Serangga } \\
\text { Air }\end{array}$} & \multirow{2}{*}{$\begin{array}{l}\text { Kualitas } \\
\text { air }\end{array}$} \\
\hline & Tipe & Jumlah & & & & & & \\
\hline \multirow[t]{4}{*}{ Sulawesi Utara } & Danau & 15 & 7 & 2 & 2 & 2 & & 6 \\
\hline & Sungai & 24 & 7 & & & & 1 & 3 \\
\hline & Rawa & & & & & & & \\
\hline & Waduk & & & & & & & \\
\hline \multirow[t]{4}{*}{ Sulawesi Tengah } & Danau & 5 & 4 & 2 & 2 & & 1 & 2 \\
\hline & Sungai & 27 & 3 & & & & & 1 \\
\hline & Rawa & & & & & & & \\
\hline & Waduk & & & & & & & \\
\hline \multirow{4}{*}{ Sulawesi Selatan } & Danau & 10 & 9 & 4 & 4 & 5 & & 5 \\
\hline & Sungai & 104 & 4 & & & & & 3 \\
\hline & Rawa & 7 & & & & & & \\
\hline & Waduk & 1 & & & & & & \\
\hline \multirow[t]{4}{*}{ Sulawesi Tenggara } & Danau & & & & & & & 8 \\
\hline & Sungai & 20 & 2 & & & & & 1 \\
\hline & Rawa & 1 & & & & & & \\
\hline & Waduk & & & & & & & \\
\hline Total & & 214 & 36 & 8 & 8 & 7 & 2 & 29 \\
\hline
\end{tabular}

3. Membuat form data berdasarkan pada data sudah dikumpulkan (Tabel 1) dimasukan kedalaman program Acssess 2000 hasilnya tercantum pada (Gambar 2a-h).

Secara teknis, aplikasi ini dilengkapi fasilitas searching untuk mempercepat pencarian informasi atau data. Untuk menjaga kualitas data akurasi dan presisi data tetap dijaga, agar informasi yang dihasilkan dapat dipertanggungjawabkan secara ilmiah serta penambahan jumlah record dan updating data tetap terus dilakukan.

\section{Kondisi Aktual Data base Keanekaragaman Hayati Perikanan Perairan Umum Daratan di Sulawesi}

Jumlah badan air yang sudah diteliti adalah 214 buah yang terdiri atas 175 buah sungai, 30 buah danau, 8 buah rawa, dan 1 waduk (Tabel 2). Jumlah sungai terbanyak di Sulawesi Selatan (104 buah), jumlah danau terbanyak di Sulawesi Utara (15 buah), jumlah rawa terbanyak di Sulawesi Selatan (7 buah), dan perairan waduk hanya 1 buah yaitu Waduk BiliBili di Sulawesi Selatan. Data biota yang paling banyak adalah ikan dengan keragaman tinggi danau, kemudian diikuti data kualitas air. Data jenis ikan perairan umum daratan terbanyak di Sulawesi Selatan, sedangkan data kualitas airnya yang terbanyak di Sulawesi Tenggara. Berdasarkan pada kondisi tersebut, maka perlu dilakukan pengkajian lebih lanjut guna mendapatkan informasi badan air yang akurat.

Bila dilihat dari jumlah badan air, sungai merupakan badan air terbanyak, namun data ikan yang tercatat baru di 17 sungai. Selanjutnya telah tercatat 21 famili, 22 genus, dan 40 spesies ikan ditemukan di Sungai Poigar (Tabel 3). Sungai Poigar 
Tabel 3.

Distribusi lkan di lokasi badan air

\begin{tabular}{|c|c|c|c|c|}
\hline \multicolumn{2}{|c|}{ Badan air } & \multirow{2}{*}{ Famili } & \multirow{2}{*}{ Genus } & \multirow{2}{*}{ Spesies } \\
\hline Nama & Tipe air & & & \\
\hline Asinua & Sungai & & & \\
\hline Bailang & Sungai & 4 & 4 & 9 \\
\hline Bantimurung & Sungai & 1 & 1 & 4 \\
\hline Betala & Sungai & 12 & 15 & 36 \\
\hline Bila & Sungai & 2 & 2 & 4 \\
\hline Kandela & Sungai & 1 & 1 & 2 \\
\hline Kasinggolan & Sungai & 3 & 4 & 6 \\
\hline Likupang & Sungai & 19 & 29 & 73 \\
\hline Molino & Sungai & 1 & 1 & 4 \\
\hline Paniki & Sungai & 1 & 1 & 1 \\
\hline Parawi & Sungai & 1 & 1 & 13 \\
\hline Poigar & Sungai & 21 & 22 & 40 \\
\hline Tanganga & Sungai & 4 & 4 & 6 \\
\hline Tindoli & Sungai & 1 & 1 & 2 \\
\hline Tobaang & Sungai & 19 & 29 & 52 \\
\hline Tondano & Sungai & 10 & 11 & 26 \\
\hline Tumokang & Sungai & 3 & 4 & 6 \\
\hline Buaya & Danau & 2 & 2 & 2 \\
\hline Kasinggolan & Danau & 23 & 34 & 65 \\
\hline Lantoa & Danau & 4 & 4 & 21 \\
\hline Limboto & Danau & 10 & 12 & 26 \\
\hline Linow & Danau & 5 & 6 & 9 \\
\hline Mahalona & Danau & 8 & 10 & 38 \\
\hline Masapi & Danau & 4 & 4 & 11 \\
\hline Matana & Danau & 10 & 11 & 38 \\
\hline Moat & Danau & 8 & 9 & 17 \\
\hline Mokobang & Danau & 2 & 2 & 4 \\
\hline Morowali & Danau & 1 & 1 & 7 \\
\hline Poso & Danau & 5 & 6 & 16 \\
\hline Sidenreng & Danau & 2 & 2 & 2 \\
\hline Taman Nasional Lore Lindu & Danau & 1 & 1 & 3 \\
\hline Tiu & Danau & 1 & 1 & 4 \\
\hline Tempe & Danau & 17 & 20 & 39 \\
\hline Tondano & Danau & 8 & 11 & 19 \\
\hline Towuti & Danau & 13 & 17 & 52 \\
\hline Umbulilin & Danau & 6 & 7 & 13 \\
\hline Wawantoa & Danau & 1 & 2 & 18 \\
\hline
\end{tabular}

merupakan outlet Danau Iloloy di Sulawesi Utara. Di Danau Kasinggolan tercatat 23 famili, 34 genus, dan 65 spesies yang ditemukan. Danau Kasinggolan terletak dalam kawasan Taman Nasional Bogani Nani Wartabone, Sulawesi Utara. Namun demikian, pengamatan lebih lanjut perlu dilakukan dalam rangka melengkapi keanekaragaman ikan di perairan umum daratan Sulawesi. Famili yang mendominansi adalah Gobiidae, Cyprinidae, dan Atherinadae.

Berdasarkan Tabel 4, plankton yang tercatat hanya sampai genus, keragaman plankton tertinggi di Danau Mahalona, Sulawesi Selatan, yaitu 8 famili dan 43 genus, kemudian Danau Lindu yang termasuk kawasan Taman Nasional Lore Lindu di Sulawesi Tengah, yaitu 7 famili dan 48 genus. Pengamatan ulang dalam rangka updating data perlu dilakukan sehingga data yang diperoleh adalah data aktual. Famili yang mendominansi adalah Chlorophyceae, Bacillariophyceae, dan Cyanophyceae.

Berdasarkan Tabel 5, data bentos baru diperoleh dari perairan sungai dan danau, perlu dilengkapi dengan mengamati bentos di badan air lainnya (sungai, rawa, dan waduk), terutama di sungai karena sungai adalah merupakan habitat bentos. Data bentos di Danau Tondano, Sulawesi Utara tercatat 7 famili, 9 genus, dan 10 spesies (Tabel 6). Selanjutnya data 
Tabel 4. Distribusi Plankton di beberapa lokasi badan air

\begin{tabular}{|c|c|c|c|}
\hline \multicolumn{2}{|c|}{ Badan air } & \multirow{2}{*}{ Famili } & \multirow{2}{*}{ Genus } \\
\hline Nama & Tipe air & & \\
\hline Asinua & Sungai & 3 & 23 \\
\hline Konaweha & Sungai & 3 & 15 \\
\hline Lahumbuti & Sungai & 3 & 11 \\
\hline Linow & Danau & 1 & 1 \\
\hline Mahalona & Danau & 8 & 43 \\
\hline Matana & Danau & 6 & 33 \\
\hline Moat & Danau & 4 & 10 \\
\hline Parawi & Sungai & 1 & 3 \\
\hline Poso & Danau & 6 & 22 \\
\hline Taman Nasional Lore Lindu & Danau & 7 & 48 \\
\hline Tempe & Danau & 3 & 4 \\
\hline Tondano & Danau & 7 & 17 \\
\hline Tondok & Sungai & 2 & 5 \\
\hline Towuti & Danau & 7 & 36 \\
\hline Parawi & Sungai & 2 & 4 \\
\hline Poso & Sungai & 1 & 1 \\
\hline Rawa Aopa & Rawa & 6 & 13 \\
\hline Wawotobi & Sungai & 2 & 9 \\
\hline
\end{tabular}

Tabel 5. Distribusi bentos di beberapa lokasi badan air

\begin{tabular}{lcccc}
\hline \multicolumn{1}{c}{ Nama badan air } & Tipe badan air & Famili & Genus & Spesies \\
\hline Mahalona & Danau & 4 & 4 & 4 \\
Buaya & Danau & 11 & 13 & 14 \\
Limboto & Danau & 2 & 2 & 2 \\
Matana & Danau & 3 & 3 & 3 \\
Sidenreng & Danau & 2 & 2 & 2 \\
Tempe & Danau & 11 & 14 & 15 \\
Tondano & Danau & 10 & 11 & 11 \\
Rawa Aopa & Rawa & 9 & 11 & 12 \\
\hline
\end{tabular}

Tabel 6. Distribusi tumbuhan air di beberapa lokasi badan air

\begin{tabular}{llccc}
\hline \multicolumn{1}{c}{ Nama badan air } & Tipe badan air & Famili & Genus & Spesies \\
\hline Mahalona & Danau & 4 & 4 & 4 \\
Buaya & Danau & 11 & 13 & 14 \\
Limboto & Danau & 2 & 2 & 2 \\
Matana & Danau & 3 & 3 & 3 \\
Sidenreng & Danau & 2 & 2 & 2 \\
Tempe & Danau & 11 & 14 & 15 \\
Tondano & Danau & 10 & 11 & 11 \\
Rawa Aopa & Rawa & 9 & 11 & 12 \\
\hline
\end{tabular}

Tabel 7. Distribusi serangga air di beberapa lokasi badan air

\begin{tabular}{|c|c|c|c|c|}
\hline Nama badan air & Tipe badan air & Famili & Genus & Spesies \\
\hline Bone & Sungai & 1 & 1 & 1 \\
\hline Poso & Danau & 4 & 9 & 9 \\
\hline
\end{tabular}


Tabel 8.

Kualitas air di beberapa lokasi badan air

\begin{tabular}{llll}
\hline \multicolumn{1}{c}{ Nama badan air } & \multicolumn{1}{c}{ Tipe } & Nama badan air & Tipe \\
\hline Ambekairi & Sungai & Parawi & Sungai \\
Asinua & Sungai & Poso & Danau \\
Benua & Sungai & Paniki & Sungai \\
Buaya & Danau & Rawa Aopa & Rawa \\
Kasinggolan & Sungai & Saddang & Sungai \\
Kumoro & Sungai & Sidenreng & Danau \\
Lahumbuti & Sungai & T.N.Lore Lindu & Danau \\
Lalimbue & Sungai & Tempe & Danau \\
Larona & Sungai & Tominanga & Sungai \\
Lausu & Sungai & Tondano & Danau \\
Linow & Danau & Tondok & Danau \\
Moat & Danau & Towuti & Danau \\
Mokobang & Danau & Tumokang & Sungai \\
Oluhuta & Sungai & Umbulilin & Danau \\
& & Wowotobi & Sungai \\
\hline
\end{tabular}

bentos di Danau Poso, Sulawesi Tengah tercatat 7 famili, 14 genus, dan 19 spesies. Famili yang mendominansi adalah Thiaridae dan Viviparidae.

Tumbuhan air pada umumnya berkembang baik di perairan dangkal dan tenang atau di tepi badan air danau dan rawa. Distribusi tumbuhan air terbanyak di Danau Buaya dan Danau Tempe, Sulawesi Selatan, Danau Tondano, Sulawesi Utara. Pengkajian tumbuhan air lebih lanjut penting untuk dilakukan guna melengkapi data base keanekaragam hayati perikanan perairan umum daratan Sulawesi. Famili yang mendominansi adalah Hydrocharitaceae, Pontederiaceae, Ceratophyllaceae, dan Cyperaceae.

Ketersediaan serangga air di setiap badan air merupakan cadangan pakan alami bagi ikan. Dibandingkan dengan biota lainnya, jenis serangga air yang tercatat sangat terbatas. Untuk itu perlu dilakukan studi atau kajian lebih banyak yang mencakup berbagai tipe badan air. Di Danau Poso, Sulawesi Tengah tercatat 4 famili, 9 genus, dan 9 spesies. Famili yang mendominansi adalah Ortoptera dan Lepidoptera (Tabel 7).

Dari 214 badan air, data kualitas air baru dikumpulkan dari 29 badan air, meliputi 14 sungai, 12 danau, dan 1 badan air rawa. Data kualitas air merupakan salah satu data yang diperlukan dalam pengelolaan sumber daya perikanan di suatu badan air. Guna mendapatkan data yang akurat dan aktual, inventarisasi dan updating data kualitas air di beberapa badan air perlu dilakukan.

Analisis berdasarkan pada data base keanekaragaman hayati perikanan perairan umum daratan di Sulawesi diperoleh informasi sebagai berikut:

1. Di Propinsi Sulawesi Utara berhasil dicatat 15 danau dan 24 sungai. Data ikan dicatat dari 7 danau dan 7 sungai. Data plankton, bentos, dan tumbuhan air dicatat dari 2 danau. Data serangga air dicatat dari 1 sungai.

2. Di Propinsi Sulawesi Tengah, berhasil dicatat 5 danau dan 27 sungai. Data ikan dicatat dari 4 danau dan 3 sungai. Data plankton dan bentos berasal dari 2 danau. Data serangga air dari 1 danau.

3. Di Propinsi Sulawesi Selatan berhasil dicatat 10 danau, 104 sungai, 7 rawa, dan 1 waduk. Data ikan dicatat dari 4 sungai.

4. Di Propinsi Sulawesi Tenggara berhasil dicatat 20 sungai dan 1 rawa. Data ikan dicatat dari 2 sungai.

\section{KESIMPULAN}

1. Data ikan terbanyak diperoleh di Danau Kasinggolan yang terletak dalam kawasan Taman Nasional Bogani Nani Wartabone, Sulawesi Utara yaitu 23 famili, 34 genus, dan 65 spesies. Di Sungai Poigar yang merupakan outlet Danau lloloy di Sulawesi Utara, tercatat 21 famili, 22 genus, dan 40 spesies ikan.

2. Data plankton yang tercatat hanya sampai dengan genus, keragaman plankton tertinggi di Danau Mahalona, Sulawesi Selatan yaitu 8 famili dan 43 genus kemudian Danau Lindu yang termasuk kawasan Taman Nasional Lore Lindu di Sulawesi Tengah yaitu 7 famili dan 48 genus. 
3. Data bentos terbanyak diperoleh di Danau Tondano, Sulawesi Utara, tercatat 7 famili, 9 genus, dan 10 spesies. Selanjutnya data bentos di Danau Poso, Sulawesi Tengah tercatat 7 famili, 14 genus, dan 19 spesies.

4. Data serangga air yang tercatat sangat terbatas. Di Danau Poso, Sulawesi Tengah tercatat 4 famili, 9 genus, dan 9 spesies.

5. Dari 214 badan air, data kualitas air baru dikumpulkan dari 29 badan air meliputi 14 sungai, 12 danau, dan 1 badan air rawa.

6. Keanekaragaman hayati perairan umum daratan Sulawesi dan pulau lainnya adalah merupakan potensi penting yang dimiliki oleh Indonesia sehingga perlu terus-menerus dikaji, diinventarisir, dijaga, dilindungi keberadaannya dan dicatat disusun dalam sebuah aplikasi program Microsoft Access 2000. Secara teknis, aplikasi ini dilengkapi fasilitas searching untuk mempercepat pencarian informasi atau data dan mudah dalam melakukan penambahan jumlah record dan updating data.

\section{SARAN}

1. Updating data perlu terus dilakukan dengan melakukan pengkajian keanekaragaman hayati (ikan, plankton, bentos, tumbuhan air, bentos, dan serangga air) perairan umum daratan Sulawesi (danau, sungai, rawa, waduk).

2. Pertemuan antara peneliti dan pemerhati lingkungan untuk melakukan tukar informasi tentang data dan informasi keanekaragaman hayati perlu secara periodik dilaksanakan sehingga diperoleh kesamaan persepsi dalam membaca dan menganalisis data yang diperoleh.

\section{PERSANTUNAN}

Kegiatan dari hasil riset keanekaragaman hayati dan bahan rumusan pengelolaan jenis ikan endemik perairan pedalaman di Sulawesi. Pusat Riset Perikanan Tangkap (PRPT), Tahun Anggaran 2005.

\section{DAFTAR PUSTAKA}

Biro Pusat Statistik Indonesia. 1996. Daftar Nama, Kode, dan Peta Wilayah Administrasi Indonesia 1996. Biro Pusat Statistik. Jakarta. Indonesia.

Global Biodiversity Information Facilities. 2005. http:/ /www.gbif.org._Tanggal 6-2-2009.

Hadiwidjaja, S. 1982. Status perikanan perairan umum daratan Sulawesi Utara. Dalam Prosiding Seminar Perikanan Perairan Umum Daratan. Badan Penelitian dan Pengembangan Pertanian. Pusat Penelitian dan Pengembangan Perikanan, Jakarta.

Haryono. 1994. Keanekaragaman jenis ikan air tawar dan potensinya di perairan sekitar kawasan Taman Nasional Bogani Nani Warta Bone Sulawesi Utara. Dalam Prosiding Seminar Hasil Penelitian dan Pengembangan Sumber Daya Hayati. Pusat Penelitian dan Pengembangan Biologi. Lembaga IImu Pengetahuan Indonesia.

Haryono \& A. Munim. 1994. Keanekaragaman jenis ikan dan ekosistemnya di sekitar kawasan pegunungan Latimojong Sulawesi Selatan. Laporan Perjalanan. Proyek Sumber Daya Hayati. Pusat Penelitian dan Pengembangan Biologi. Lembaga Ilmu Pengetahuan Indonesia. Bogor.

Roemantyo, B. Hartoko, M. Ridwan, B. Rahman, S. Pramono, R Widodo, Y. E. Pertiwi, Jumadi, A. Pramana, \& H. I. P. Utaminingrum. 2004a. Flora and Fauna Dictionary. Pusat Penelitian Biologi. Lembaga Ilmu Pengetahuan Indonesia. Bogor.

Roemantyo, B. Hartoko, M. Ridwan, H. I. P. Utaminingrum, R. Widodo, B. Rahman, Jumadi, Pramana, \& Y. E. Pertiwi. 2004b. Geography Information System: Biodiversity. Pusat Penelitian Biologi-Lembaga IImu Pengetahuan Indonesia. Bogor. 